\title{
ВMJ Global Health Creating a specialist physician workforce in low-resource settings: reflections and lessons learnt from the East African Training Initiative
}

\author{
Neil W Schluger, ${ }^{1}$ Charles B Sherman, ${ }^{2}$ Amsalu Binegdie, ${ }^{3}$ \\ Tewedros Gebremariam, ${ }^{3}$ Dawit Kebede, ${ }^{3}$ Aschalew Worku, ${ }^{3}$ E Jane Carter, ${ }^{2}$ \\ Otto Brändli ${ }^{4}$
}

\begin{abstract}
To cite: Schluger NW, Sherman CB, Binegdie A, et al. Creating a specialist physician workforce in lowresource settings: reflections and lessons learnt from the East African Training Initiative. BMJ Glob Health 2018;3:e001041. doi:10.1136/ bmjgh-2018-001041
\end{abstract}

Handling editor Sanni Yaya

Received 5 July 2018

Revised 9 August 2018

Accepted 24 August 2018

Check for updates

(C) Author(s) (or their employer(s)) 2018. Re-use permitted under CC BY-NC. No commercial re-use. See rights and permissions. Published by BMJ.

${ }^{1}$ Departments of Medicine, Epidemiology and Environmental Health Science, Columbia University Vagelos College of Physicians and Surgeons and Mailman School of Public Health, New York City, New York, USA

2Department of Medicine, Warren Alpert Medical School of Brown University, Providence, Rhode Island, USA

${ }^{3}$ Department of Medicine, Addis Ababa University School of Medicine/Tikur Anbessa Specialized Hospital, Addis Ababa, Ethiopia

${ }^{4}$ Swiss Lung Foundation, Wald, Switzerland

Correspondence to

Dr Neil W Schluger;

ns311@cumc.columbia.edu

\section{ABSTRACT}

Many African countries have extremely low ratios of physicians to population, and there are very, very few specialists. This leaves most patients without access to specialised care, and importantly also leaves many countries with insufficient expertise to properly evaluate the burden of illness and the needs of the population overall. The challenges to training a specialised physician workforce in resource-limited settings are many, and they go far beyond the (relatively simple) task of transmission of clinical skills. We initiated a capacity-building programme to train pulmonary physicians in Ethiopia, a country of 105 million persons with a high burden of lung disease that had no prior existing training programme in pulmonary medicine. Using volunteer faculty from the USA and Europe, we have provided high-quality training and established a cohort of pulmonary specialists there. We have identified several components of training that go beyond clinical skills development but which we feel are crucial to sustainability. These components include the delineation of viable career pathways that allow professional growth for subspecialist physicians and that support the permanent establishment of a local faculty; the development of important non-clinical skills, including leadership and pedagogical techniques; training in clinical research methodologies; and the development of mechanisms to amplify the impact of a still relatively small number of specialised physicians to address the needs of the population generally. Our programme, the East African Training Initiative, has successfully addressed many of these challenges and we hope that it can be replicated elsewhere.

\section{INTRODUCTION}

Creating a trained physician workforce in sub-Saharan Africa is an urgent need, although the means to accomplish are not always well defined, and few successful models exist. ${ }^{1}$ The ratio of physicians to population in most African countries is extremely low, and in all cases much, much lower than in most

\section{Summary box}

- There are several components to creating capacity for advanced clinical training in low-resource settings.

- Straightforward, on-site didactic clinical training is necessary but not sufficient to achieve this capacity-building goal.

- Leadership and administrative skills must be developed by the trainees in order to create sustainable structures and local training programmes.

- Professional development and career pathways for trainees must be identified, nurtured and supported.

- The effect of training even a relatively small number of specialists and subspecialists can be magnified through effective partnerships with health ministries, development of professional societies and through advocacy efforts in public health.

of Asia, Europe and the Americas. In high-income countries, the ratio of physicians to 1000 persons is in the 2-5 range. In most of Africa, the ratio is less than $0.5 / 1000$, with many countries having a ratio of below $0.1 / 1000{ }^{2}$ Additionally, in most African countries the majority of the physician workforce consists of general doctors who have often received only a brief period of clinical training after graduation from medical school. There are few specialists and very, very few subspecialists. ${ }^{34}$ In addition, most of the existing physicians are concentrated in urban areas, while most Ethiopians live in rural settings.

Ethiopia, whose 105000000 inhabitants make it Africa's second most populous country, is a prime example of this situation. The ratio of physicians to population is no more than $0.025 / 1000$ persons, among the lowest in the world. Although the optimal ratio of physicians to populations is unknown, ${ }^{5}$ Ethiopia's ratio is far below the benchmark of 
the ratio of 0.55 physicians $/ 1000$ persons that would be needed to attend $80 \%$ of all live births. ${ }^{1}$ Although there are few official government data regarding the numbers and types of specialists in the country, a survey published in 2016 indicated that $84.2 \%$ of the physician workforce were general practitioners, and that $57 \%$ of those physicians had 3 years or less of work experience. ${ }^{6}$ A 2016 survey done by the Federal Ministry of Health indicated that there were perhaps only 6983 physicians in total in the country, of whom 5447 were general practitioners, with only 268 internists and a total of 124 subspecialists of any kind. ${ }^{7}$

For many years, there were only three medical schools serving the country, in the capital of Addis Ababa, in Gondar and in Jimma. In response to the enormous need for doctors in Ethiopia, the government has opened many more new medical schools in the past few years, and there are now more than 32 in the country. ${ }^{8}$ This has created another problem. There is a lack of faculty to train the graduates in various medical specialties (internal medicine, surgery, paediatrics, anaesthesia, and obstetrics and gynaecology), not to mention the near total lack of faculty needed to train subspecialists.

Several years ago, in response to an overture from the leadership of the Addis Ababa University College of Health Sciences, we created the East African Training Initiative (EATI), a programme designed to train a critical mass of physicians in clinical pulmonary and critical care medicine who could then go on to themselves serve as faculty for further training of physician subspecialists. We have previously described the genesis and structure of the programme. ${ }^{9} 10$ Having led this programme for 5 years, we offer now a perspective on the structural challenges and obstacles to creating and sustaining a cadre of specialist and subspecialist physicians in a low-resource setting. We also offer our perspective on how a relatively small number of highly trained subspecialists can magnify their impact on a population basis. We think that the lessons we have learnt in Ethiopia are broadly applicable to other resource-limited settings where there are few specialist and subspecialist physicians.

\section{CLINICAL TRAINING: THE (RELATIVELY) EASY PART}

The clinical training in EATI was modelled closely on fellowship training programmes in the USA and Europe. To date we have graduated nine trainees, and five are currently still in training, with continuing plans to train two to three news fellows each year. We developed a formal curriculum, which was approved by the appropriate local regulatory authorities, and we recruited a large group of generous volunteer faculty who have travelled to Ethiopia to be in residence for 2-4 weeks at a time. To graduate, fellows must pass rigorous written and oral bedside exams. Faculty were vetted for important characteristics of cultural awareness and sensitivity, scholarly achievement (nearly all have been full-time faculty at leading academic centres) and effectiveness as teachers.
We succeeded in having faculty on the ground for roughly $75 \%-80 \%$ of the time. These faculty performed the roles that are customary and familiar in training programmes elsewhere: leading bedside teaching rounds; giving didactic lectures and conferences; and teaching procedural skills such as bronchoscopy, bedside ultrasound, pleural biopsy, central line insertion, chest tube placement and tracheal intubation.

We feel strongly that the success and sustainability of the clinical training that we provided has depended greatly on the physical presence of our faculty in Addis Ababa on a nearly continuous basis. We have incorporated distance learning tools such as internet-based lectures and interactive case-based discussions and conferences as extremely useful adjuncts, but they are only adjuncts. There is no training programme anywhere in the USA that would allow its fellows to be trained with only 3 or 4 months of direct faculty supervision and teaching with 8-9 months of distance learning. Accepting a lower standard will mean accepting less well-trained physicians, and we think it is best to try to avoid 'the soft bigotry of low expectations'. We realise of course that our programme has been a relatively small one, and we relied greatly on very dedicated volunteers. This creates serious issues of scalability, although anecdotally there seems to be an increasing number of American and European physicians interested in working in low/middle-income country settings. Still, we are not aware of successful models where highly trained physicians are produced without this type of education.

Our trainees benefitted greatly from having a number of faculty participate in the programme, rather than just one or two who were in residence for prolonged periods. At present, we have one visiting faculty member and three to four Ethiopian faculty (all trained in our programme) and five to six fellows at any given time. This provides a faculty to fellow ratio of $1: 1-1.5$, which meets the standard set by the Accreditation Council on Graduate Medical Education in the USA. Such an arrangement exposed them to a variety of perspectives and approaches to clinical care, and this too mirrors the best training programmes in resource-rich settings. This approach ensures that faculty will sustain a high level of energy and enthusiasm and will be less likely to burn out. Also, there are relatively few physicians who can devote long stretches of time away from their primary job and home.

\section{CREATING A CAREER PATHWAY FOR SUBSPECIALISTS}

To encourage training of specialists and subspecialists, there must also be a career track that allows those physicians who have undertaken that training to use their advanced skills and knowledge in a way that is personally and professionally satisfying. As with physicians anywhere in the world, this kind of satisfaction rests on a mix of tangible and intangible aspects of one's career. These include wages, professional recognition and status, but 
also the kind of satisfaction that comes from building structures that endure, and from teaching and training generations of students, house staff and fellows.

Beyond the personal satisfaction of using the newly acquired skills that advanced training provides, the establishment of paid staff and faculty positions in public hospitals and academic institutions amplifies the effect of training by providing a venue and faculty to better educate medical students and general physicians in the various medical and surgical specialties (a version of a 'train the trainer' concept). Thus, the physicians trained in our programme are now providing better education to the house staff and to undergraduate medical students about the aetiology, diagnosis and treatment of common and important lung diseases such as asthma, chronic obstructive pulmonary disease (COPD), and environmental and occupational lung disease. A similar effort is occurring in critical care. This is much needed, as recently 20 new intensive care units have opened in district hospitals that lack trained critical care specialists.

As some of our graduates have returned to regions away from Addis Ababa, where they are the only trained subspecialists, there is a risk of professional isolation. To address this, the central staff at Black Lion is in the process of establishing a Pulmonary Project Echo, a web-based knowledge-sharing network, ${ }^{11}$ to link the entire graduating group together around case discussions and ongoing guideline management to create an ongoing supportive learning community, meeting every other week as a group.

For all of the above to happen, academic institutions and ministries of health and education must provide a commitment to support and sustain the graduates of any advanced specialty or subspecialty programme. If such support is not provided, and opportunities for the kind of personal and professional benefits described above do not exist, it will be difficult to convince physicians to pursue advanced training. In addition, for those that do, the temptation to take the acquired skills elsewhere will be great, and the only consequence from advanced training will be accelerated brain drain.

\section{DEVELOPMENT OF NON-CLINICAL SKILLS}

As our own programme has progressed, we have appreciated more and more the importance of creating the structures in which these types of activities can exist, and the importance of developing the skills needed to sustain them. In the USA and Europe, we often take for granted that our academic specialty departments and divisions are capable of providing education for students and house officers, or for running outpatient chest clinics, or pulmonary function laboratories, or bronchoscopy suites. However, in order for those things to happen there must be physician leaders with the pedagogic skills, administrative capabilities, organisational talents and motivation to create those realities. It did not take long for us to realise that leadership and administrative training were as important as clinical training if we were to build lasting capacity. Helping trainees establish priorities in programme building, learn about issues of personnel management, understand procurement of supplies and navigating institutional politics is also part of training. Goodwill is not enough. We now incorporate formal didactic sessions for these activities. In addition, on an ongoing basis, we meet formally with the graduates of our programme who have assumed leadership positions within the programme to discuss these aspects of programme building. These ongoing mentoring and coaching activities have been well received, and build on the personal experiences of the faculty as role models.

\section{CREATING CAPACITY FOR RESEARCH}

Creating research capacity was not an initial primary goal of our programme, nor do we think it is the most urgent need for training programmes in most low-resource settings. The vast majority of physicians working in most countries around the world are engaged in clinical care and not investigation. However, as our programme was located within a medical school, we felt it was in fact important to develop this capacity. We have found, as our programme has grown, that the opportunity to participate in research is one of the strongest attractions for potential trainees, for a number of reasons. The physicians we have trained have enthusiastically embraced the research enterprise ${ }^{12-16}$ and in fact have spurred us to devote quite a bit of time and effort to its development.

Participation in research provides many of the same rewards to physicians and investigators in low-resource settings as it does anywhere else. The intellectual satisfaction of creating new knowledge, the sense that one is addressing important challenges in one's own environment, the interaction with colleagues doing similar work in other regions, the ability to travel to international conferences to present one's work and to learn from other researchers all apply in Ethiopia and elsewhere as much as they do in Europe or the USA. In order to support these activities a training programme must provide training and mentorship in research methods and grant writing, and support for travel. Many of our volunteer faculty are successful clinician scientists, but we have also relied heavily for research training on programmes such as the American Thoracic Society's Methods in Epidemiology, Clinical and Operations Research programme, as well as workshops offered by various professional societies at regional and international meetings.

\section{USING PUBLIC HEALTH APPROACHES TO AMPLIFY THE EFFECTS OF ADVANCED SPECIALTY AND SUBSPECIALTY TRAINING}

Training (initially) a small number of subspecialists could not be reasonably expected to have a significant impact on health and well-being on a population basis. Certainly, there are some patients who do in fact benefit directly from the creation of a cadre of physicians with advanced 
training. In our programme, we have established robust and busy inpatient and outpatient services, and a type and level of care that was not previously available is now being provided in the largest public hospital in Addis Ababa. Still, in a country of over 100 million persons, the population-level impact of those services is modest. In order to leverage the training and training programme to address the health and medical needs of a population, structures must be created to amplify the effect of training.

The burden of chronic lung disease in Africa in general and in Ethiopia in particular is difficult to state with precision, as there are few population-based surveys to rely on. The burden is likely to be very large though. A recent study from Malawi found that $40 \%$ of adults there had abnormal pulmonary function test results. The Global Burden of Disease project estimates that chronic obstructive lung disease and asthma in Ethiopia together represent nearly $2.5 \%$ of all deaths in the country, for example. ${ }^{17}$ In a manner similar to the multiplier effect of having EATI physicians provide more sophisticated training to medical students, house officers and general doctors, using advocacy and technical assistance can also have a great effect.

As an example, the graduates of our programme created the Ethiopian Thoracic Society (ETS). The ETS sponsors a yearly meeting that draws attention to lung health issues of major public health impact. In 2018, for example, the theme of the meeting was 'Prevent and Stop Smoking'. The meeting was attended by high-ranking officials from several government ministries and from the US Agency for International Development, members of civil society, journalists, representatives from allied health professions and physicians from several medical specialties. The conference highlighted the threat of tobacco to the health of the country. The establishment of organisations such as ETS allows the messages of great public health importance (previous years' conferences focused on the health effects of indoor and outdoor air pollution and tuberculosis) to reach broader audiences in multiple sectors of society.

Since the inception of our programme, its leadership (the Ethiopian physicians who have been trained and who now direct the Pulmonary and Critical Care Division at Black Lion Hospital) has maintained close relationships with the Ministry of Health. They have worked with the Ministry to create national standards and guidelines related to education and patient care in several important areas of lung health and critical illness including asthma, critical illness, COPD and tuberculosis. Graduates from our programme have also joined national governmental technical advisory panels for tuberculosis and primary care. Importantly, some of these guidelines have been incorporated into educational initiatives for general doctors working in primary care. These efforts may improve care of patients beyond those who are cared for at large public teaching hospitals.

Training programmes cost money. We have existed solely because of the generosity of Vital Strategies and the Swiss Lung Foundation. There are far too few funding sources for programmes like ours. That deficit limits reproducibility and sustainability. There are myriad programmes aimed at funding research in low-resource settings, or at using adjunct distant learning methods for clinical training, and for providing short-term training opportunities for physicians from low-resource settings to be in residence for periods of time in high-resource training programmes. However, it is apparent to us that there is not enough support for the more prosaic aspects of clinical training that are necessary to provide the physician workforce needed in many countries. To address this will require an examination of governmental priorities in those countries, and encouragement of philanthropic efforts elsewhere.

\section{CONCLUSION}

Of the nine graduates of our programme, all remain in Ethiopia, working almost exclusively in the public sector. Five are now staff and faculty at Tikur Anbessa/Black Lion Hospital. Others are at public hospitals in Addis Ababa, Mekele and Bahir Dar. Two current trainees will join a third graduate next year at a second hospital in Addis with the goal of launching a fellowship programme there in the next 2 years. We are hopeful and optimistic that these transitions will be successful. A great deal will depend on local financial support for faculty and fellow positions from the Addis Ababa University School of Medicine, the administration of Black Lion Hospital and the Federal Ministry of Health. Because of recent political changes in Ethiopia there is a great sense of optimism in the country and there seems to be a realisation that investment in the health sector is of great importance. The country has opened over 20 new medical schools in the past few years, and there seems to be recognition at high levels of the government of the need for an expanded, well-trained physician workforce. ${ }^{18}$ There is no question that a programme such as ours could not have developed to the point that it has without the willing and supportive partnership of the medical school, hospital and Ministry of Health. The entire impetus for the programme in fact came from our Ethiopian partners. For such a programme to be replicated elsewhere will require a similar partnership and commitment.

Our intention in writing this piece was to provide insight into establishing lasting capacity for the development of specialist and subspecialist physicians in low-resource settings. We are aware of several such initiatives in many parts of the world, including a programme recently developed through the US Peace Corps called the Global Health Services Partnership, which has placed physicians in year-long training positions in Liberia, Tanzania, Malawi and Uganda. ${ }^{19} 20$ We feel that in order for these efforts to be successful and sustainable, attention must be given to much more than straightforward, didactic clinical training, and engagement with many sectors is necessary. 
A successful programme includes: identification of a qualified faculty that can provide reliable and nearly constant clinical instruction on the ground; the creation and support of career pathways for specialists; leadership training that allows for the development of didactic and administrative skills needed for the transition to sustainable, locally run training programmes; opportunities for continuing education, research training and professional development; and engagement with academic and government partners to create programmes in advocacy and public health.

The ultimate goal of any programme such as ours should be to transfer full responsibility for leadership and continuing training to the local partners after a period of years. In our own programme, after training five classes of fellows, we are making the transition to having our graduates assume day-to-day responsibility for clinical training. We have reduced the number of faculty who travel to Ethiopia and our faculty now focus much more on professional development and research training. This will be crucial to establishing true independence and sustainability, though we envision a long-lasting professional collaboration between many of our faculty and Ethiopian colleagues. Our aim has always been to create local capacity rather than to provide ongoing aid.

Contributors NWS is a director of the East African Training Initiative. He wrote the initial draft of the manuscript and participated in all revisions of it. CBS, EJC and $\mathrm{OB}$ are directors of the East African Training Initiative. They reviewed and made revisions to all versions of the manuscript. $A B, T G, D K$ and $A W$ are former trainees and current faculty members of the East African Training Initiative. They reviewed and made revisions to all versions of the manuscript.

Funding Training programme cost money. We have existed solely because of the generosity of Vital Strategies and the Swiss Lung Foundation. There are far too few funding sources for programme like ours. That deficit limits reproducibility and sustainability. There are myriad programme aimed at funding research in low-resource settings, or at using adjunct distant learning methods for clinical training, and for providing short-term training opportunities for physicians from low-resource settings to be in residence for periods of time in high-resource training programme. However, it is apparent to us that there is not enough support for the more prosaic aspects of clinical training that are necessary to provide the physician workforce needed in many countries. To address this will require an examination of governmental priorities in those countries, and encouragement of philanthropic efforts elsewhere.

Competing interests None declared.

Patient consent Not required.

Provenance and peer review Not commissioned; externally peer reviewed.

Data sharing statement There are no additional data available.

Open access This is an open access article distributed in accordance with the Creative Commons Attribution Non Commercial (CC BY-NC 4.0) license, which permits others to distribute, remix, adapt, build upon this work non-commercially, and license their derivative works on different terms, provided the original work is properly cited, appropriate credit is given, any changes made indicated, and the use is non-commercial. See: http://creativecommons.org/licenses/by-nc/4.0/

\section{REFERENCES}

1. Scheffler RM, Liu JX, Kinfu Y, et al. Forecasting the global shortage of physicians: an economic- and needs-based approach. Bull World Health Organ 2008;86:516-23.

2. WHO, 2018. Density of physicians. Available from: http://www.who. int/gho/health_workforce/physicians_density/en/ [accessed 14 Mar 2018].

3. Feysia B, Herbst C, Lemma W. The health work force in Ethiopia: addressing the remaining challenges. Washington, DC: The World Bank, 2012.

4. Kinfu Y, Dal Poz MR, Mercer H, et al. The health worker shortage in Africa: are enough physicians and nurses being trained? Bull World Health Organ 2009;87:225-30.

5. Zurn P, Dal Poz MR, Stilwell B, et al. Imbalance in the health workforce. Hum Resour Health 2004;2:13.

6. Assefa T, Haile Mariam D, Mekonnen W, et al. Physician distribution and attrition in the public health sector of Ethiopia. Risk Manag Healthc Policy 2016;9:285-95.

7. Worku A. Report from the Federal Ministry of Health Regarding the Physician Workforce in Ethiopia 2016.

8. Derbew M, Animut N, Talib ZM, et al. Ethiopian medical schools' rapid scale-up to support the government's goal of universal coverage. Acad Med 2014;89(8 Suppl):S40-4.

9. Sherman CB, Carter EJ, Braendli O, et al. The East African Training Initiative. A model training program in pulmonary and critical care medicine for low-income countries. Ann Am Thorac Soc 2016;13:451-5

10. Schluger NW, Sherman C. Notes from the field. Training pulmonary specialists in a low-income country. Ann Am Thorac Soc 2015;12:467-8.

11. The University of New Mexico, 2018. Project Echo. Available from: https://echo.unm.edu/ [accessed 6 Aug 2018].

12. Gebremariam TH, Binegdie AB, Mitiku AS, et al. Level of asthma control and risk factors for poor asthma control among clinic patients seen at a Referral Hospital in Addis Ababa, Ethiopia. BMC Res Notes 2017;10:558.

13. Binegdie AB, Parekh M, Tolessa TB, et al. Sequelae of patients treated for pulmonary tuberculosis in chest clinic, Tikur Anbessa Specialized Hospital (TASH), Addis Ababa, Ethiopia. Ethiop Med J 2015;53:167-71.

14. Ayele $\mathrm{Y}$, Engidawork E, Bayisa T. Assessment of inhaled corticosteroids use and associated factors among asthmatic patients attending Tikur Anbessa Specialized Hospital, Ethiopia. BMC Res Notes 2017;10:314.

15. Nwankwo ONO, Mokogwu N, Agboghoroma O, et al. Knowledge, attitudes and beliefs about the health hazards of biomass smoke exposure amongst commercial food vendors in Nigeria. PLoS One 2018;13:e0191458.

16. Lee A, Adobamen PR, Agboghoroma O, et al. Household air pollution: a call to action. Lancet Respir Med 2015;3:e1-2.

17. Global Burden of Disease, 2018.

18. WHO, 2013. Wanted: more and better-trained health workers. Available from: http://www.who.int/features/2013/ethiopia-healthworkforce/en/ [accessed 30 Jul 2018].

19. Mullan F, Kerry VB. The global health service partnership: teaching for the world. Acad Med 2014;89:1146-8.

20. Kerry VB, Mullan F. Global Health Service Partnership: building health professional leadership. Lancet 2014;383:1688-91. 